\title{
IDENTIFICAÇÃO DE BACTÉRIAS PSICROTRÓFICAS PROTEOLÍTICAS ISOLADAS DE LEITE CRU REFRIGERADO E CARACTERIZAÇÃO DO SEU POTENCIAL DETERIORADOR
}

\section{Identification of proteolytic psychrotrophic bacteria isolated from refrigerated raw milk and characterization of its spoilage potential}

\author{
Cláudia Lúcia de Oliveira Pinto ${ }^{1 *}$, Solimar Gonçalves Machado², \\ Maurilio Lopes Martins ${ }^{3}$, Maria Cristina Dantas Vanetti ${ }^{2}$
}

\begin{abstract}
RESUMO
Os objetivos deste estudo foram identificar bactérias psicrotróficas proteolíticas isoladas de leite cru refrigerado, avaliar o seu poder deteriorador e a sua capacidade de adesão em superfícies de aço inoxidável sob temperaturas de refrigeração. Dentre as bactérias gram-positivas, 23,81\% e 33,33\% dos isolados pertenciam aos gêneros Bacillus e Paenibacillus respectivamente. No grupo de bactérias gram-negativas fermentadoras de glicose foram identificados os gêneros Cedecea, Enterobacter, Hafnia, Klebsiella, Pantoea, Providencia, Rhanella e Serratia e dentre as bactérias gram-negativas não-fermentadoras, os gêneros Acinetobacter, Aeromonas, Burkholderia, Chryseobacteriun (Flavobacterium), Chryseomonas, Moraxella e Pseudomonas. O gênero Pseudomonas foi predominante entre as bactérias identificadas e representou $33,98 \%$ do total de isolados. Dentre as bactérias fermentadoras de glicose $14,6 \%, 15,3 \%$ e $20,8 \%$ dos isolados apresentaram predominantemente atividade proteolítica a $6,5{ }^{\circ} \mathrm{C}, 21{ }^{\circ} \mathrm{C}$ e $35^{\circ} \mathrm{C}$, respectivamente, enquanto as bactérias gram-negativas não-fermentadoras apresentaram $25 \% \mathrm{e}$ $23,6 \%$ dos isolados com atividades associadas de proteases, lipases e lecitinases a $6,5{ }^{\circ} \mathrm{C}$ e $21{ }^{\circ} \mathrm{C}$, respectivamente, o que indicou maior potencial deteriorador. Em espécies de bactérias gram-negativas e gram-positivas, constatou-se a produção de enzimas termorresistentes e adesão à superfície de aço inoxidável a $6,5{ }^{\circ} \mathrm{C}$. Os resultados deste estudo reforçaram a importância da implementação das boas
\end{abstract}

1 Empresa de Pesquisa Agropecuária de Minas Gerais (EPAMIG), Unidade Regional Zona da Mata, Campus UFV, Caixa Postal 216, 36571-000, Viçosa, MG, Brasil. E-mail: claudia.epamig@gmail.com

2 Universidade Federal de Viçosa (UFV), Departamento de Microbiologia, Viçosa, MG, Brasil.

3 Instituto Federal de Educação, Ciência e Tecnologia do Sudeste de Minas Gerais (IFET), Rio Pomba, MG, Brasil.

* Autor para correspondência.

Recebido / Received: 11/02/2015

Aprovado / Approved: 25/05/2015 
práticas de produção e de fabricação na cadeia produtiva do leite para fins de prevenção de sua deterioração e minimização de perdas de qualidade e econômicas.

Palavras-chave: deterioração; enzimas hidrolíticas; adesão; Pseudomonas.

\begin{abstract}
This study aimed to identify proteolytic psychrotrophic bacteria isolated from refrigerated raw milk, to evaluate their spoilage potencial and their capability of adhesion to stainless steel surfaces at cold temperatures. Among gram-positive bacteria, 23.81\% and 33.33\% of isolates belonged to Bacillus and Paenibacillus genera. In the gram-negative glucose fermentative bacteria group, the genera Cedecea, Enterobacter, Hafnia, Klebsiella, Pantoea, Providencia, Rhanella and Serratia were identified, while the genera Acinetobacter, Aeromonas, Burkholderia, Chryseobacteriun (Flavobacterium), Chryseomonas, Moraxella and Pseudomonas were identified among gram-negative non fermentative microorganisms. The genus Pseudomonas, which was predominant, represented $33.98 \%$ of total isolates. Among fermenters of glucose bacteria, $14.6 \%, 15.3 \%$ and $20.8 \%$ of isolates showed predominantly proteolytic activity at $6.5,21$ and $35{ }^{\circ} \mathrm{C}$, respectively, while $25 \%$ e $23.6 \%$ of isolates belonging the gram-negative non-fermenting microorganisms showed associated activities of proteases, lipases and lecithinases at 6.5 and $21{ }^{\circ} \mathrm{C}$, respectively, emphasizing their greatest spoilage potential. Gram-positive and gram-negative bacteria produced heat resistant proteolytic enzymes and adhesion to stainless steel surfaces at $6.5^{\circ} \mathrm{C}$. The results of this study reinforce the importance of the implementation of good manufacturing practices in order to prevent milk spoilage and minimize economic and quality losses.
\end{abstract}

Keywords: spoilage; hydrolytic enzymes; adherence; Pseudomonas.

\section{INTRODUÇÃO}

A refrigeração do leite recém-ordenhado foi introduzida no Brasil na segunda metade da década de 90 com o objetivo de reduzir a deterioração por microrganismos mesófilos, sendo regulamentada pela Instrução Normati-

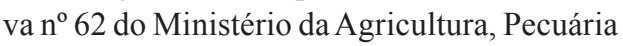
e Abastecimento (BRASIL, 2011). No entanto, o armazenamento do leite em temperaturas na faixa de $4{ }^{\circ} \mathrm{C}$ a $10{ }^{\circ} \mathrm{C}$ não previne a multiplicação de bactérias psicrotróficas, as quais crescem em temperaturas entre $0{ }^{\circ} \mathrm{C}$ e $7{ }^{\circ} \mathrm{C}$ (JAY, 2005).

Alguns estudos foram realizados com o objetivo de caracterizar a microbiota psicrotrófica presente no leite cru e identificar a microbiota predominante após armazenamento sob refrigeração. Hantis-Zacharov; Halpern (2007) e Raats et al. (2011) utilizaram métodos convencionais de cultivo e moleculares e evidenciaram que Pseudomonas, Acinetobacter e actinobactérias são os grupos dominantes no leite refrigerado israelense. O gênero Pseudomonas também foi considerado o grupo predominante, com elevado potencial deteriorador de leite nos Estados Unidos (DOGAN; BOOR, 2003), na Bélgica (MARCHAND et al., 2009b), no Canadá (RASOLOFO et al., 2010) e na Itália (ERCOLINI et al., 2009). Pinto et al. (2006) e Nörnberg et al. (2010) demonstraram que bactérias gram-negativas predominam no leite cru refrigerado brasileiro. 
Embora a maioria dos microrganismos psicrotróficos seja inativada pelos tratamentos térmicos utilizados na indústria, o estudo de organismos produtores de enzimas hidrolíticas, a exemplo das proteases e lipases, tem despertado interesse de pesquisadores (KOHLMANN et al., 1991; MARCHAND et al., 2008; IZIDORO et al., 2013).

A maioria das enzimas proteolíticas produzidas por psicrotróficos é termoestável, portanto, apresenta atividade residual após a pasteurização ou processamento a ultra-alta temperatura (UAT) ou em inglês ultra high temperature (UHT) (SØRHAUG; STEPANIAK, 1997; NIELSEN, 2002; BAGLINIÈRE et al., 2013). As proteases termorresistentes hidrolisam todos os tipos de caseína (BAGLINIÈRE et al., 2012) o que está associado à ocorrência de problemas tecnológicos em produtos de vida útil longa, como a gelificação e a sedimentação do leite UHT, além de sabores indesejáveis em produtos derivados e redução do rendimento na fabricação de queijos (SØRHAUG; STEPANIAK, 1997; VESCONSI et al., 2012). A desestabilização das micelas de caseína, causada pela ação de proteases, resulta na redução do rendimento na fabricação de queijos e consequentes perdas econômicas e de qualidade (NIELSEN, 2002; CARDOSO, 2006).

Algumas bactérias psicrotróficas proteolíticas podem formar biofilmes em superfícies de equipamentos e utensílios utilizados na produção de lácteos. Nesta condição, estes microrganismos são mais resistentes à ação de agentes químicos e físicos utilizados na sanitização por produzirem grande quantidade de substâncias poliméricas extracelulares que representam uma barreira de proteção e produzem mais proteases quando comparados às células livres (TEH et al., 2012).

As alterações dos componentes do leite em função da multiplicação dos microrganismos psicrotróficos proteolíticos causam perdas econômicas consideráveis. Objetivou-se identificar bactérias psicrotróficas proteolíticas isoladas de leite cru refrigerado, avaliar o potencial deteriorador e a capacidade de adesão em superfícies de aço inoxidável destes organismos sob refrigeração.

\section{MATERIAL E MÉTODOS}

\section{Identificação dos isolados}

Foram isoladas 153 bactérias psicrotróficas proteolíticas de leite cru refrigerado coletado em tanques coletivos e individuais de propriedades rurais, Zona da Mata, Minas Gerais durante a estação da seca (PINTO, 2004). Para a coleta, manuseio e manutenção das amostras, seguiu-se o procedimento da Federação Internacional de Laticínios (IDF, 1985).

Os isolados foram inicialmente caracterizados quanto à morfologia, atividades de oxidase e catalase e coloração de Gram. O metabolismo fermentativo da glicose foi pesquisado nos isolados gram-negativos em meio Rugai modificado (MBiolog Diagnósticos Ltda., Contagem, Brasil). Para identificação utilizou-se os sistemas API 20 E ou API 20 NE (BioMérieux, La Balme les Grottes, France) e Bac Tray (Difco ${ }^{\circledR}$, Lawrence, EUA). Os isolados gram-positivos foram identificados por Microbial Identification System - MIS, versão 4.0 .

\section{Caracterização da produção de protea- ses, lipases e lecitinases em diferentes temperaturas}

A capacidade de produção de proteases, lipases e lecitinases dos isolados foi avaliada em ágar SMCA (FRANK et al., 1992), ágar Tributirina e ágar Tripicaseína e Soja - TSA, suplementados com 5\% de suspensão de gema de ovo, respectivamente (VANDERZANT; SPLITTSOESSER, 1992). As placas foram incubadas a $6,5^{\circ} \mathrm{C}$, por 
10 dias, e a $21{ }^{\circ} \mathrm{C}$ e $35^{\circ} \mathrm{C}$, por 72 horas, respectivamente. Após o período de incubação, verificou-se a presença de halo de clarificação e, ou, precipitação da caseína para proteólise, clarificação para lipólise e clarificação ou precipitação da lecitina para lecitinase, nos respectivos meios.

\section{Quantificação da atividade proteolítica e termoestabilidade das enzimas}

A quantificação da atividade proteolítica em sobrenadantes de culturas de isolados psicrotróficos proteolíticos foi realizada conforme técnica descrita por Ewings et al. (1984). As culturas puras foram cultivadas em 4 mL de Caldo Infusão de Cérebro e Coração - BHI, a $22{ }^{\circ} \mathrm{C}$, por 48 horas por duas vezes consecutivas. Após este período de incubação, foram centrifugadas a $3.000 \mathrm{~g}$, por 20 minutos. Uma alíquota de $1 \mathrm{~mL}$ do sobrenadante foi adicionada a tubos de aço inoxidável (7,4 x $127 \mathrm{~mm})$, com paredes de espessura de $0,25 \mathrm{~mm}$, climatizados em banho de óleo a $100{ }^{\circ} \mathrm{C}$. A amostra foi tratada por 30 segundos e, após este tempo, foi imediatamente resfriada em banho de água gelada por um minuto. Amostras foram avaliadas quanto à atividade de proteases, misturando-se: $1 \mathrm{~mL}$ de solução de azocaseína (Sigma, Chemical Co-St Louis, MO, USA) $0,5 \%(\mathrm{p} / \mathrm{v})$ em tampão Tris- $\mathrm{HCl} 0,1 \mathrm{~mol} / \mathrm{L}$, $\mathrm{pH} 7,5 ; 1 \mathrm{~mL}$ de Tris-HCl 0,1 mol/L, pH 7,5 e $0,2 \mathrm{~mL}$ de amostra. Após incubação a $37^{\circ} \mathrm{C}$, por duas horas em banho-maria, adicionou-se à mistura de reação igual volume de ácido tricloroacético - TCA a 10\% (m/v), seguindose de transferência dos tubos para banho de gelo, por 15 minutos. As amostras foram clarificadas por centrifugação a $5.000 \mathrm{~g}$, por 10 minutos, e a absorvância do sobrenadante foi medida a $366 \mathrm{~nm}$, em espectrofotômetro Micronal, modelo B 582. Uma unidade de atividade proteolítica é definida como a concentração de enzima requerida para produzir um aumento na absorvância em $0,01 \mathrm{~h}^{-1}$ e a termoestabilidade, como a capacidade do sobrenadante em reter pelo menos $50 \%$ da atividade em relação às amostras não submetidas ao tratamento térmico.

\section{Adesão em aço inoxidável}

Foram selecionados para a avaliação da capacidade de adesão à superfície de aço inoxidável em leite a $6,5 \pm 0,5{ }^{\circ} \mathrm{C}$ isolados com maior atividade de lecitinase, lipolítica e proteolítica, representantes da microbiota contaminante do leite cru. Avaliou-se isolados gram-positivos (Lactococcus sp. (035), Bacillus amiloliquefaciens (119), Staphylococcus sciuri (052) e Paenibacillus macerans (105)) e gram-negativos (P. fluorescens (07 A, 041), Pseudomonas fluorescens ATCC 13525, Acinetobacter lowffi (09), Serratia liquefaciens (020, 021, 039), Klebsiella oxytoca (093)). Cupons de prova de aço inoxidável AISI 304, de dimensão $10 \mathrm{~mm} \times 10 \mathrm{~mm} \times 1 \mathrm{~mm}$, foram preparados de acordo com Jeong; Frank (1994). As culturas foram ativadas, por duas vezes consecutivas, em intervalos de 24 horas, em leite desnatado reconstituído (LDR) 12\%, a $25{ }^{\circ} \mathrm{C}$. Os cupons de teste foram imersos, separadamente, em tubos de ensaio contendo $5 \mathrm{~mL}$ de LDR $12 \%$ esterilizado, inoculado com, aproximadamente, $10^{3}$ a $10^{4} \mathrm{UFC} / \mathrm{mL}$ da suspensão do microrganismo teste. $\mathrm{O}$ número de células aderidas por $\mathrm{cm}^{2}$ foi determinado após 48 horas de contato com a superfície. Para o controle de adesão inicial, os cupons foram colocados em contato com o leite inoculado e imediatamente retirados para análise. A adesão bacteriana foi observada por técnica de microscopia de epifluorescência. Em condições assépticas, os cupons foram rinsados com $10 \mathrm{~mL}$ de solução de tampão fosfato, esterilizada $\left(\mathrm{KH}_{2} \mathrm{PO}_{4}\right.$, $\mathrm{pH} 7,2)$, por 1 minuto. Os cupons foram depositados em lâmina de vidro para microscopia, colocados em uma placa de Petri e inundados com solução de Kirkpatrick, 
contendo álcool isopropílico, clorofórmio e formaldeído na proporção de $6: 3: 1$, durante 3 minutos, para fixação das bactérias aderidas. Posteriormente, os cupons foram corados com uma solução aquosa do corante alaranjado de acridina $0,04 \%$, por 5 minutos. Os cupons foram observados em microscópio ótico LEICA DMLS, em objetiva de imersão adaptada à microscopia de epifluorescência. Foram contadas as bactérias que emitiam fluorescência vermelho-alaranjada.

\section{RESULTADOS E DISCUSSÃO}

\section{Identificação dos isolados}

Dentre as 136 bactérias psicrotróficas proteolíticas isoladas de amostras de leite cru refrigerado, 30 eram gram-positivas $(22 \%)$ e 106 gram-negativas (78\%). A microbiota gram-positiva incluiu os gêneros Bacillus, Paenibacillus, Staphylococcus, Lactobacillus e Enterococcus. Bacillus e Paenibacillus foram isolados com maior frequência (Tabela 1). A contaminação do leite com bactérias formadoras de esporos dos gêneros Bacillus e Paenibacillus representa o principal fator limitante da vida útil de produtos lácteos quando a contaminação pós-pasteurização é controlada (MARTIN et al., 2011). De acordo com dados descritos por Chen et al. (2003), espécies do gênero Bacillus foram detectadas em leite UHT e, em alguns casos, em contaminações altas, como $10^{5} \mathrm{UFC} / \mathrm{mL}$.

No grupo de bactérias gram-negativas fermentadoras de glicose foram identificados os gêneros Cedecea, Enterobacter, Hafnia, Klebsiella, Pantoea, Providencia, Rhanella e Serratia e dentre as bactérias gram-negativas não-fermentadoras, os gêneros Acinetobacter, Aeromonas, Burkholderia, Chryseobacteriun (Flavobacterium), Chryseomonas, Moraxella e Pseudomonas. O gênero Pseudomonas representou o maior percentual do total de bactérias identificadas, sendo a espécie predominante
P. fluorescens (Tabela 1). De fato, espécies do gênero Pseudomonas são descritas como os principais organismos predominantemente isolados de leite cru refrigerado associados à deterioração do leite devido à sua capacidade de produzir enzimas termorresistentes (ARCURI et al., 2008; DE JONGHE et al., 2011; CLETO et al., 2012; DECIMO et al., 2014; SCATAMBURLO et al., 2015).

\section{Caracterização da produção de proteases, lipases e lecitinases}

As bactérias gram-positivas apresentaram predominância de atividade proteolítica, com um baixo percentual de isolados produtores de lipases e lecitinases concomitantemente (Figura 1a). Dentre as bactérias gram-negativas fermentadoras de glicose, que representaram $46,2 \%$ do total de isolados, constatou-se a predominância de isolados que apresentaram apenas atividade proteolítica a $6,5^{\circ} \mathrm{C}, 21{ }^{\circ} \mathrm{C}$ e $35^{\circ} \mathrm{C}$. Isolados com atividades de lipase e de lecitinase associadas foram observados em menor proporção (Figura 1b). Entretanto, maior proporção de bactérias gram-negativas não-fermentadoras apresentou atividade proteolítica associada à atividade de lipase e lecitinase a $6,5{ }^{\circ} \mathrm{C}$ e $21{ }^{\circ} \mathrm{C}$ (Figura 1c). Neste grupo de bactérias encontram-se as espécies de Pseudomonas. O aumento da temperatura para $35{ }^{\circ} \mathrm{C}$ reduziu o percentual de isolados gram-negativos não-fermentadores com atividade simultânea dos três tipos de enzimas (Figura 1c). Em resultados constatados por Dogan; Boor (2003), 69\% dos isolados de $P$. fluorescens apresentaram atividades proteolíticas e de lecitinase, enquanto apenas $14,5 \%$ dos isolados de $P$. putida produziram essas enzimas hidrolíticas.

A síntese de enzimas é heterogênea mesmo quando bactérias da mesma espécie são consideradas como demonstrado por Marchand et al. (2009a). A variação da produção de proteases pode estar associada à 
Tabela 1 - Identificação de bactérias psicrotróficas proteolíticas isoladas de leite cru refrigerado granelizado

\begin{tabular}{|c|c|c|c|c|}
\hline \multirow[b]{2}{*}{ Gênero } & \multirow[b]{2}{*}{ Espécie } & \multicolumn{3}{|c|}{ Percentuais (\%) } \\
\hline & & $\begin{array}{c}\text { Gram- } \\
\text { positivos }\end{array}$ & $\begin{array}{l}\text { Do total } \\
\text { isolado }\end{array}$ & $\begin{array}{c}\text { Do Total } \\
\text { identificado }\end{array}$ \\
\hline \multirow{3}{*}{ Bacillus } & B. amyloliquefaciens & 14,29 & 1,96 & 2,20 \\
\hline & B. subtilis & 4,76 & 0,66 & 0,74 \\
\hline & Bacillus sp. & 4,76 & 0,66 & 0,74 \\
\hline \multirow{2}{*}{ Paenibacillus } & P. alvei & 9,52 & 1,31 & 1,47 \\
\hline & P. macerans & 23,81 & 3,27 & 3,68 \\
\hline Staphylococcus & S. sciuri & 4,76 & 0,66 & 0,74 \\
\hline \multirow{2}{*}{ Lactobacillus } & L. fermentum & 4,76 & 0,66 & 0,74 \\
\hline & L. plantarum & 4,76 & 0,66 & 0,74 \\
\hline \multirow{2}{*}{ Lactococcus } & L. lactis subespécie cremoris & 4,76 & 0,66 & 0,74 \\
\hline & Lactococcus sp. & 9,52 & 1,31 & 1,47 \\
\hline \multirow{2}{*}{ Enterococcus } & E. faecalis & 4,76 & 0,66 & 0,74 \\
\hline & E. faecium & 9,52 & 1,31 & 1,47 \\
\hline \multirow[t]{2}{*}{ Não-identificados } & - & 5,94 & - & \\
\hline & & $\begin{array}{c}\text { Gram- } \\
\text { positivos }\end{array}$ & $\begin{array}{c}\text { Do total } \\
\text { isolado }\end{array}$ & $\begin{array}{c}\text { Total } \\
\text { identificado }\end{array}$ \\
\hline Acinetobacter & A. lwoffi & 0,87 & 0,65 & 0,74 \\
\hline Aeromonas & A. hydrophila & 5,22 & 3,92 & 4,41 \\
\hline \multirow[t]{2}{*}{ Burkholderia } & B. cepacia & 1,74 & 1,31 & 1,47 \\
\hline & B. pseudomallei & 1,74 & 1,31 & 1,47 \\
\hline Cedecea & C. lapagei & 2,61 & 1,96 & 2,20 \\
\hline $\begin{array}{l}\text { Chryseobacterium } \\
\text { (Flavobacterium) }\end{array}$ & C. meningosepticum & 1,74 & 1,31 & 1,47 \\
\hline Chryseomonas & C. luteola & 1,74 & 1,31 & 1,47 \\
\hline \multirow{3}{*}{ Enterobacter } & E. cloacae & 1,74 & 1,31 & 1,47 \\
\hline & E. gergoviae & 0,87 & 0,65 & 0,74 \\
\hline & E. sakasaki & 2,61 & 1,96 & 2,20 \\
\hline Hafnia & H. alvei & 2,61 & 1,96 & 2,20 \\
\hline \multirow{2}{*}{ Klebsiella } & K. oxytoca & 1,74 & 1,31 & 1,47 \\
\hline & K. ozanae & 4,35 & 3,27 & 3,68 \\
\hline Moraxella & M. catharralis & 6,09 & 4,56 & 5,15 \\
\hline Pantoea & P. agllomerans & 3,48 & 2,61 & 2,94 \\
\hline Providencia & P. stuartii & 0,87 & 0,65 & 0,74 \\
\hline \multirow{3}{*}{ Pseudomonas } & P. fluorescens & 39,15 & 29,41 & 33,31 \\
\hline & P. putida & 5,22 & 3,92 & 4,44 \\
\hline & P. stutzeri & 0,87 & 0,65 & 0,74 \\
\hline Rhanella & R. aquatilis & 2,61 & 1,96 & 2,20 \\
\hline \multirow{2}{*}{ Serratia } & S. liquefaciens & 10,43 & 7,84 & 8,82 \\
\hline & S. odorifera & 1,74 & 1,31 & 1,47 \\
\hline
\end{tabular}


heterogeneidade na expressão gênica ou na atividade enzimática. Além disso, essa variabilidade na regulação gênica pode ser dependente da temperatura (NICODÈME et al., 2005). Nicodème et al. (2005) destacaram que determinada temperatura pode ser ótima para produção de proteases para uma espécie e um fator limitante para outra, embora o efeito da temperatura de crescimento na produção de enzima extracelular não dependa do gênero das estirpes (BUCHON et al., 2000). Apesar da heterogeneidade na regulação e expressão gênica, a produção de enzimas extracelulares acontece no final da fase $\log$ e na fase estacionária (HELLIO et al. 1993; MAKHZOUM et al., 1995; RAJMOHAN et al. 2002).
Como observado por Nero et al. (2009), a maioria das amostras de leite cru coletadas em propriedades rurais $(36,6 \%)$ apresentava contagens de bactérias psicrotróficas entre $10^{3}$ e $10^{4} \mathrm{UFC} / \mathrm{mL}$. Considerando que a legislação brasileira vigente (BRASIL, 2011) exige que o leite cru seja armazenado sob refrigeração até o processamento, Machado et al. (2013) constataram que os microrganismos proteolíticos de amostras de leite cru com contagens de psicrotróficos entre $10^{3}$ e $10^{4} \mathrm{UFC} / \mathrm{mL}$ atingem o final da fase logarítmica após 48 horas. Esses autores ainda observaram a produção de protease e a deterioração do leite devido à hidrólise da $\kappa$-caseína após o tempo de armazenamento de 48 horas.

(a)

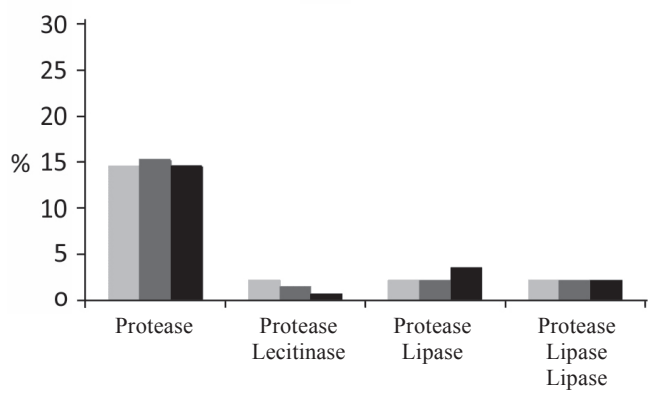

(b)

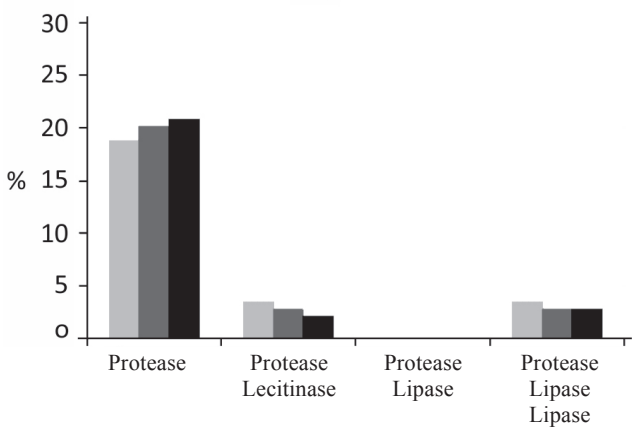

(c)

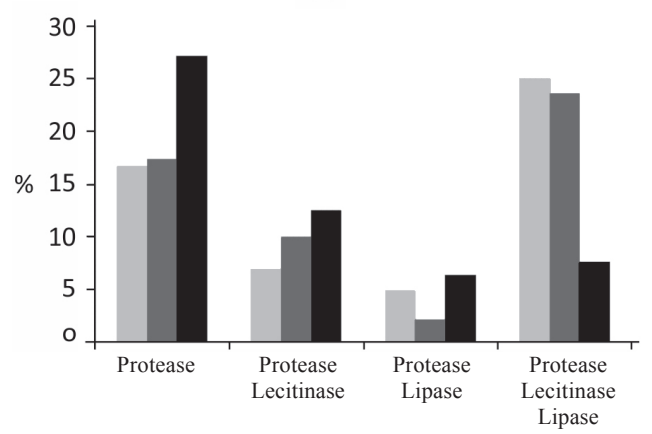

Figura 1 - Distribuição do percentual de isolados com atividades de enzimas hidrolíticas, proteases, lipases e lecitinases a $6,5{ }^{\circ} \mathrm{C}(\square), 21{ }^{\circ} \mathrm{C}(\square)$ e $35^{\circ} \mathrm{C}(\square)$. (a) gram-positivos, (b) gram-negativos fermentadores e (c) gram-negativos não-fermentadores 
Tabela 2 - Atividade proteolítica de bactérias psicrotróficas gram-negativas e gram-positivas isoladas de leite cru refrigerado antes e após tratamento térmico do sobrenadante a $100{ }^{\circ} \mathrm{C}$, por 30 segundos

\begin{tabular}{|c|c|c|c|}
\hline Espécie & $\begin{array}{l}\text { Código do } \\
\text { isolado }\end{array}$ & $\begin{array}{c}\text { Unidades de } \\
\text { enzima/hora (antes } \\
\text { tratamento térmico) }\end{array}$ & $\begin{array}{c}\text { Atividade } \\
\text { proteolítica residual } \\
(\%)\end{array}$ \\
\hline \multicolumn{4}{|c|}{ Gram-positivos } \\
\hline \multirow{5}{*}{ Bacillus amiloliquefaciens } & 048 & 10,95 & $-9,59$ \\
\hline & 0104 & 21,05 & $-8,55$ \\
\hline & 0105 & 19,60 & $-9,44$ \\
\hline & 0113 & 6,80 & 119,85 \\
\hline & 0151 & 23,50 & 45,32 \\
\hline Paenibacillus macerans & 0150 & 8,45 & $-7,69$ \\
\hline \multirow{2}{*}{ Bacillus alvei } & 0135 & 7,25 & 19,31 \\
\hline & 0147 & 8,05 & $-11,18$ \\
\hline \multicolumn{4}{|c|}{ Gram-negativos } \\
\hline \multirow{3}{*}{ Aeromonas hydrophila } & 037 & 16,15 & 87,93 \\
\hline & 042 & 3,90 & 119,23 \\
\hline & 0113 & 6,80 & 119,85 \\
\hline \multirow{2}{*}{ Burkholderia cepacia } & 05 & 19,55 & 83,38 \\
\hline & 0112 & 1,70 & 144,12 \\
\hline Chryseomonas luteola & 0107 & 2,30 & 113,04 \\
\hline \multirow{13}{*}{ Pseudomonas fluorescens } & 07A & 1,90 & 113,16 \\
\hline & 07B & 3,00 & 53,33 \\
\hline & 033 & 4,10 & 103,66 \\
\hline & 041 & 2,80 & 83,93 \\
\hline & 072 & 7,35 & 93,20 \\
\hline & 077 & 9,60 & 85,42 \\
\hline & 096 & 2,05 & 80,49 \\
\hline & 097 & 1,15 & 100,00 \\
\hline & 0123 & 2,00 & 122,50 \\
\hline & 0126 & 8,00 & 90,62 \\
\hline & 0137 & 0,75 & 73,33 \\
\hline & 0138 & 2,55 & 156,86 \\
\hline & 0141 & 9,80 & 80,10 \\
\hline \multirow{3}{*}{ Serratia liquefaciens } & 020 & 5,75 & 101,74 \\
\hline & 021 & 1,15 & 91,30 \\
\hline & 039 & 1,40 & 96,43 \\
\hline
\end{tabular}




\section{Quantificação da atividade proteolítica e termoestabilidade das enzimas}

Dentre os isolados gram-positivos, foi observada a atividade proteolítica antes do tratamento térmico em bactérias dos gêneros Bacillus e Paenibacillus. Dentre os sete isolados do gênero Bacillus, três apresentaram atividade proteolítica residual após o tratamento térmico do sobrenadante (Tabela 2). De acordo com Chen et al. (2003), espécies do gênero Bacillus possuem, em geral, alta atividade proteolítica extracelular e intracelular, e produzem enzimas resistentes aos processamentos térmicos como pasteurização e tratamento UHT.

Alta atividade proteolítica residual foi constatada no sobrenadante de bactérias gram-negativas dos gêneros Aeromonas, Burkholderia, Chryseomonas, Pseudomonas e Serratia (Tabela 2). Algumas estirpes produziram proteases termorresistentes com atividade residual superior a $100 \%$. Embora as modificações estruturais ocasionadas pelo tratamento térmico na molécula dessas proteases ainda não tenham sido elucidadas, é possível que uma alteração na conformação da enzima aumente a sua atividade.

Marchand et al. (2008) constataram que amostras de leite cru refrigerado apresentavam $73 \%$ de atividade proteolítica residual após tratamento térmico a $95^{\circ} \mathrm{C}$ por $8,45 \mathrm{~min}$. Baglinière et al. (2013) demonstraram que a protease termorresistente AprX produzida por P. fluorescens e inoculada no leite cru na concentração de $0,2 \mathrm{mg} / \mathrm{L}$ pode causar a desestabilização do produto tratamento termicamente a $140{ }^{\circ} \mathrm{C}$ por $4 \mathrm{~s}$ (UHT) após apenas oito dias de estocagem a $20^{\circ} \mathrm{C}$. Outros estudos recentes também destacaram o potencial deteriorador de bactérias isoladas de leite (DE JONGHE et al., 2010; TEH et al., 2014; SCATAMBURLO et al., 2015).

\section{Adesão em aço inoxidável}

P. fluorescens, A. lowffi, S. liquefaciens, K. oxytoca, Lactococcus sp., B. amiloliquefaciens, $S$. sciuri e $P$. macerans foram capazes de aderir à superfície de aço inoxidável a $7^{\circ} \mathrm{C}$. O número de células aderidas variou de $10^{2}$ a $10^{5}$ células $\mathrm{cm}^{-2}$ (Tabela 3 ). Observou-se

Tabela 3 - Logaritmo do número de células de bactérias psicrotróficas proteolíticas gram-negativas e gram-positivas aderidas por $\mathrm{cm}^{2}$, em superfície de aço inoxidável ASI 304, após crescimento em leite desnatado por 48 horas, a $7^{\circ} \mathrm{C}$

\begin{tabular}{cc}
\hline Bactérias & Logaritmo de células aderidas $\mathrm{cm}^{-2}$ \\
\hline P. fluorescens 041 & 5,00 \\
P. fluorescens 07A & 4,95 \\
Acinetobacter lowffi 09 & 4,59 \\
Serratia liquefaciens 020 & 4,23 \\
Serratia liquefaciens 021 & 4,22 \\
Serratia liquefaciens 039 & 4,01 \\
Klebsiella oxytoca 093 & 3,96 \\
Pseudomonas fluorescens ATCC 13525 & 3,62 \\
Lactococcus sp. 035 & 3,57 \\
Bacillus amiloliquefaciens 0119 & 3,30 \\
Staphylococcus sciuri 052 & 2,97 \\
Paenibacillus macerans 0105 & 2,62 \\
\hline
\end{tabular}


maior número de células aderidas de bactérias gram-negativas e dentre estes isolados, $P$. fluorescens se destacou, resultado que reforça seu potencial deteriorador (Tabela 3). Cleto et al. (2012) sugerem que estas bactérias formadoras de biofilme vivem em uma relação simbiótica, em que Pseudomonas spp. partilha os sideróforos essenciais que libera em quantidade elevada, enquanto recebe ajuda estrutural e proteção física de outros gêneros. A formação de biofilmes mistos em tanques de refrigeração de leite pode comprometer a qualidade e a vida de prateleira dos produtos (TEH et al., 2014). A capacidade dos isolados de colonizar as superfícies de processamento e formar biofilme está diretamente relacionada à presença destes microrganismos após o tratamento térmico e, consequente deterioração do leite.

\section{CONCLUSÃO}

A microbiota psicrotrófica proteolítica de leite cru refrigerado é composta de bactérias gram-positivas e predominantemente gram-negativas. Apresenta alto potencial deteriorador associado à produção de enzimas proteolíticas termorresistentes, além de lecitinases e lipases, em especial a microbiota gram-negativa e capacidade de adesão em superfícies de aço inoxidável à temperatura de refrigeração como $6,5^{\circ} \mathrm{C}$. Assim, os resultados deste estudo permitem reforçar a importância da prevenção de contaminações do leite cru por meio da implementação das boas práticas agropecuárias para minimizar perdas de qualidade dos produtos, rendimento na fabricação de queijos e consequentemente perdas econômicas.

\section{REFERÊNCIAS}

ARCURI, E. F. et al. Contagem, isolamento e caracterização de bactérias psicrotróficas contaminantes de leite cru refrigerado. Ciência Rural, v. 38, n. 8, p. 2250-2255, 2008.
BAGLINIÈRE, F. et al. Proteolysis of ultra high temperature-treated casein micelles by AprX enzyme from Pseudomonas fluorescens $\mathrm{F}$ induces their destabilization. International Dairy Journal, v. 31, n. 2, p. 55-61, 2013.

BAGLINIÈRE, F. et al. Quantitative and qualitative variability of the caseinolytic potential of different strains of Pseudomonas fluorescens: Implications for the stability of casein micelles of UHT milks during their storage. Food Chemistry, v. 135, n. 4, p. 2593-2603, 2012.

BRASIL. Ministério da Agricultura, Pecuária e Abastecimento. Instrução Normativa $\mathrm{n}^{\circ} 62$, de 29 de dezembro de 2011. Aprova o Regulamento Técnico de Produção, Identidade e Qualidade do Leite tipo A, o Regulamento Técnico de Identidade e Qualidade de Leite Cru Refrigerado, o Regulamento Técnico de Identidade e Qualidade de Leite Pasteurizado e o Regulamento Técnico da Coleta de Leite Cru Refrigerado e seu Transporte a Granel, em conformidade com os Anexos desta Instrução Normativa. Diário Oficial da República Federativa do Brasil, Brasília, 30 dez. 2011. Seção 1, p. 6.

BUCHON, L. et al. Temperature dependence of extracellular enzymes production by psychrotrophic and psychrophilic bacteria. Biotechnology Lettres, v. 22, n. 19, p. 1577-1581, 2000 .

CARDOSO, R. R. Influência da microbiota psicrotrófica no rendimento de queijo Minas Frescal elaborado com leite estocado sob refrigeração. 2006. 57 p. Dissertação (Mestrado em Microbiologia Agrícola). Curso de Pós-graduação em Microbiologia Agrícola, Universidade Federal de Viçosa, Viçosa, 2006.

CHEN, L.; DANIEL, R. M.; COOLBEAR, T. Detection and impact of protease and lipase activities in milk and milk powders. International Dairy Journal, v. 13, n. 4, p. 255-275, 2003.

CLETO, S. et al. Characterization of contaminants from a sanitized milk processing plant. PLoS ONE, v. 7, n. 6, p. e40189, 2012. 
DE JONGHE, V. et al. Influence of storage conditions on the growth of Pseudomonas species in refrigerated raw milk. Applied and Environmental Microbiology, v. 77, n. 2, p. 460-470, 2011.

DE JONGHE, V. et al. Toxinogenic and spoilage potential of aerobic spore-formers isolated from raw milk. International Journal of Food Microbiology, v. 136, n. 3, p. 318-25, 2010.

DECIMO, M. et al. Characterization of gramnegative psychrotrophic bacteria isolated from Italian bulk tank milk. Journal of Food Science, v. 79, n. 10, p. M2081-M2090, 2014.

DOGAN, B.; BOOR, K. J. Genetic diversity and spoilage potentials among Pseudomonas spp. isolated from fluid milk products and dairy processing plants. Applied and Environmental Microbiology, v. 69, n. 1, p. 130-138, 2003.

ERCOLINI, D. et al. Molecular identification of mesophilic and psychrotrophic bacteria from raw cow's milk. Food Microbiology, v. 26, n. 2, p. 228-231, 2009.

EWINGS, K. N.; O’CONNOR, R. E.; MITCHELL, G. E. Proteolytic microflora of refrigerated raw milk in south east Queensland. The Australian Journal of Dairy Technology, v. 39, n. 2, p. 65-68, 1984.

FRANK, J. F.; CHRISTEN, G. L.; BULLERMAN, L. B. Tests for groups of microorganisms. In: MARSHALL, R. T. (Ed.). Standard methods for the examination of dairy products. New York: APHA, 1992. p. 271-286.

HANTIS-ZACHAROV, E.; HALPERN, M. Culturable psychrotrophic bacterial communities in raw milk and their proteolytic and lipolytic traits. Applied and Environmental Microbiology, v. 73, n. 22, p. 7162-7168, 2007.

HELliO, F. C.; ORANGE, N.; GUESPINMICHEL, J. F. Growth temperature controls the production of a single extracellular protease by
Pseudomonas fluorescens MFO, in the presence of various inducers. Research in Microbiology, v. 144 , n. 8 , p. $617-625,1993$.

INTERNATIONAL DAIRY FEDERATION (IDF). Milk and milk products - Methods of sampling. Brussels, 1985. 19 p. (International Standard, 50B).

IZIDORO, T. B. et al. Effect of psychrotrophic growth on the milk fat fraction at different temperatures of storage. Journal of Food Science, v. 11, n. 10, p. 1750-1754, 2013

JAY, J. M. Microbiologia de Alimentos. 6. Porto Alegre: Artmed, 2005. 711 p.

JEONG, D. K.; FRANK, J. F. Growth of Listeria monocytogenes at $10{ }^{\circ} \mathrm{C}$ in biofilms with microorganisms isolated from meat and dairy processing environments. Journal of Food Protection, v. 57, n. 7, p. 576-586, 1994.

KOHLMANN, K. L.; NIELSEN, S. S.; LADISCH, M. R. Purification and characterization of an extracellular protease produced by Pseudomonas fluorescens M3/6. Journal of Dairy Science, v. 74, n. 12, p. 4125-4136, 1991.

MACHADO, S. G.; BAZZOLLI, D. M. S.; VANETTI, M. C. D. Development of a PCR method for detecting proteolytic psychrotrophic bacteria in raw milk. International Dairy Journal, v. 29, n. 1, p. 8-14, 2013.

MAKHZOUM, A.; KNAPP, J. S.; OWUSU, R. K. Factors affecting growth and extracellular lipase production by Pseudomonas fluorescens 2D. Food Microbiology, v. 12, p. 277-290, 1995.

MARCHAND, S. et al. Selective determination of the heat-resistant proteolytic activity of bacterial origin in raw milk. International Dairy Journal, v. 18, n. 5, p. 514-519, 2008.

MARCHAND, S. et al. Heterogeneity of heatresistant proteases from milk Pseudomonas species. International Journal of Food Microbiology, v. 133, n. 1-2, p. 68-77, 2009a. 
MARCHAND, S. et al. Seasonal influence on heatresistant proteolytic capacity of Pseudomonas lundensis and Pseudomonas fragi, predominant milk spoilers isolated from Belgian raw milk samples. Environmental Microbiology, v. 11, n. 2 , p. $467-482,2009 b$.

MARTIN, N. H. et al. Results from raw milk microbiological tests do not predict the shelf-life performance of commercially pasteurized fluid milk. Journal of Dairy Science, v. 94, n. 3, p. 1211-1222, 2011.

NERO, L. A.; VIÇOSA, G. N.; PEREIRA, F. E. V. Qualidade Microbiológica do leite determinada por características de produção. Ciência e Tecnologia de Alimentos, v. 29, n. 2, p. 386390, 2009 .

NICODÈME, M. et al. Extracellular protease activity of different Pseudomonas strains: dependence of proteolytic activity on culture conditions. Journal of Applied Microbiology, v. 99, p. 641-648, 2005.

NIELSEN, S. S. Plasmin system and microbial proteases in milk: characteristics, roles and relationship. Journal of Agricultural and Food Chemistry, v. 50, n. 22, p. 6628-6624, 2002.

NORNBERG, M.F.B.L. et al. Proteolytic activity among psychrotrophic bacteria isolated from refrigerated raw milk. International Journal of Dairy Technology, v. 63, n. 1, p. 4146, 2010.

PINTO, C. L. O. Bactérias psicrotróficas proteolíticas do leite cru refrigerado granelizado destinado à produção do leite UHT. 2004. 97 p. Tese (Doutorado em Microbiologia Agrícola). Curso de Pós-graduação em Microbiologia Agrícola, Universidade Federal de Viçosa, Viçosa, 2004.

PINTO, C. L. O.; MARTINS, M. L.; VANETTI, M. C. D. Qualidade microbiológica de leite cru refrigerado e isolamento de bactérias psicrotróficas proteolíticas. Ciência e Tecnologia de Alimentos, v. 26, n. 3, p. 645- 651, 2006.
RAATS, D. et al. Molecular analysis of bacterial communities in raw cow milk and the impact of refrigeration on its structure and dynamics. Food Microbiology, v. 28, n. 3, p. 465-471, 2011

RAJMOHAN, S.; DODD, C. E. R.; WAITES, W. M. Enzymes from isolates of Pseudomonas fluorescens involved in food spoilage. Journal of Applied Microbiology, v. 93, n. 2, p. 205 213, 2002.

RASOLOFO, E. A. et al. Molecular analysis of bacterial population structure and dynamics during cold storage of untreated and treated milk. International Journal of Food Microbiology, v. 138, n. 1-2, p. 108-118, 2010.

SCATAMBURLO et al. Spoilage potential of Pseudomonas species isolated from goat milk. Journal of Dairy Science, v. 98, n. 2, p. 759764, 2015.

SØRHAUG, T.; STEPANIAK, L. Psychrotrophs and their enzymes in milk and dairy products: Quality aspects. Trends in Food Science \& Technology, v. 8, n. 2, p. 35-41, 1997.

TEH, K. H. et al. Proteolysis produced within biofilms of bacterial isolates from raw milk tankers. International Journal of Food Microbiology, v. 157, n. 1, p. 28-34, 2012.

TEH, K. H. et al. Proteolysis in ultra-heattreated skim milk after exposure to multispecies biofilms under conditions modelling a milk tanker. International Journal of Dairy Technology, v. 67, n. 2, p. 176-181, 2014.

VANDERZANT, C. E.; SPLITTSOESSER, D. F. Compendium of methods for the microbiological examination of foods. 3 . Washington: American Public Health Association (APHA), 1992.

VESCONSI, C. N.; VALDUGA, A. T.; CICHOSKI, A. J. Sedimentação do leite UHT integral, semidesnatado e desnatado durante armazenamento. Ciência Rural, v. 42, n. 4, p. 730-736, 2012 